\title{
Influence of Kiln Atmosphere on Chemical States of Iron in Red Clay
}

\author{
Mitsuru WAKAMATSU, Nobuyuki TAKEUCHI, Ohn MAUNG, \\ Gao-Chao LAI and Shingo ISHIDA* \\ Department of Inorganic Materials, Faculty of Engineering and Design, Kyoto Institute of Technology \\ Matsugasaki, Sakyo-ku, Kyoto-shi 606 \\ * Department of Industrial Chemistry, Chubu University
}

\section{赤色粘土中の鉄の化学状態に炉内雾囲気が与える影響}

\author{
若松 盈・竹内信行 · Ohn Maung ·頼 高潮・石田信伍 ${ }^{*}$ \\ $\left(\begin{array}{l}\text { 京都工芸瀻維大学 工芸学部 無機材料工学科 } \\ * \text { 中部大学 } \text { 工業化学科 }\end{array}\right.$
}

\begin{abstract}
The chemical states of iron in fired red clay containing iron in high concentration and the phase transformation occurring during firing in various atmospheres were studied by X-ray diffraction, ESR and ESCA. It was pointed out that the reduction of Fe ions to metallic iron and the formation of hercynite $\left(\mathrm{FeAl}_{2} \mathrm{O}_{4}\right)$ took place competitively during the firing of the clay at $1000^{\circ}-1200^{\circ} \mathrm{C}$ under reducing conditions. The color of the clay fired below $1250^{\circ} \mathrm{C}$ in a reducing atmosphere was dependent only on the firing temperature, but not on the atmosphere.

[Received November 2, 1985]
\end{abstract}

Key-words : Furnace atmosphere, Red clay, Color of fired clay, $\mathrm{FeAl}_{2} \mathrm{O}_{4}$

\section{Introduction}

The mechanical and the optical properties of red clay fired at $1250^{\circ} \mathrm{C}$ under various atmospheric conditions has been described in the previous paper ${ }^{1)}$. The bloating and the blackening of fired clay were observed to be prevalent when firing was performed in reducing atmosphere ${ }^{1)-5}$. Iron, under the mild reducing condition, was in the ferrous state and sometimes metallic iron was observed when the firing was carried out under strongly reducing conditions ${ }^{1), 6)-9)}$. The presence of hercynite in the clay fired below $1250^{\circ} \mathrm{C}$ was briefly mentioned ${ }^{1), 10)}$. In this paper, the stability of hercynite phase, namely, its formation and disappearance under various firing conditions is discussed in detail in connection with the chemical states of iron in the fired clay.

\section{Experimental}

The firing of the samples were performed in the same way as described in the previous paper ${ }^{1}$. The fired samples were measured with X-ray diffraction, ESR, ESCA and color spectrometers. In ESR measurements, the signals of manganese ion were taken as the standard signals for determining the magnetic field. For ESCA measurements, the peak of $\mathrm{C}_{1}$ s was taken as the standard peak for determining the binding energy which appears at $285.0 \mathrm{eV}$ and then, the peak of Si $2 \mathrm{p}$ was again determined. The binding energy values of $\mathrm{Fe} 2 \mathrm{p}_{3 / 2}$ peaks for those samples were determined by the assuming that the binding energy of Si $2 \mathrm{p}$ did not change for all samples fired under any atmospheric condition. The argon etching treatment was performed for $5 \mathrm{~min}$ to remove the impurities covering the surface of the samples.

\section{Results and discussion}

3.1 X-ray diffraction analysis of red clay

Table 1 shows the components present in red clay fired at different temperatures and atmospheric conditions ${ }^{11,12)}$. Gas compositons of the kiln atmospheres are shown in Table $2^{1)}$. In a strongly reducing atmosphere, that is at $m=0.7$ ( $m=$ air ratio), metallic iron was observed at low temperature $\left(1000^{\circ} \mathrm{C}\right)$, but at $1100^{\circ} \mathrm{C}$, the hercynite phase was present, and above $1200^{\circ} \mathrm{C}$, the metallic iron phase was again observed. This fact strongly indicates that two competitive reactions occurred simultaneously, namely, the reduction to metallic iron and the hercynite formation. The hercynite must be formed at the expense of the decomposed products of clay minerals, such as 
Table 1. The X-ray diffraction analysis of red clay fired in different temperatures and atmospheres.

\begin{tabular}{|c|c|c|c|c|c|c|c|}
\hline $\begin{array}{l}\text { Air } \\
\text { ratio } \\
(-)\end{array}$ & $\begin{array}{l}\text { Keep } \\
\text { temp. } \\
\left({ }^{\circ} \mathrm{C}\right)\end{array}$ & $\alpha$-Quartz & $\alpha$-Cristobalite & Mullite & Iron & Hercynite & Hematite \\
\hline \multirow[t]{5}{*}{0.7} & 1000 & + & & & + & + & \\
\hline & 1100 & + & & + & & + & \\
\hline & 1150 & + & & + & & + & \\
\hline & 1200 & + & & + & + & & \\
\hline & 1250 & + & + & + & + & & \\
\hline \multirow[t]{4}{*}{0.8} & 1000 & + & & & + & + & \\
\hline & 1100 & + & & + & & + & \\
\hline & 1200 & + & + & + & + & & \\
\hline & 1250 & + & + & + & + & & \\
\hline \multirow[t]{4}{*}{0.9} & 1000 & + & & & & + & \\
\hline & 1100 & + & + & + & & + & \\
\hline & 1200 & + & + & + & & + & \\
\hline & 1250 & + & + & + & & & \\
\hline 1.0 & 1250 & + & & + & & & + \\
\hline 1.2 & 1250 & + & & + & & & + \\
\hline 1.4 & 1250 & + & & + & & & + \\
\hline 1.6 & 1250 & + & & + & & & + \\
\hline
\end{tabular}

Table 2. Gas compositions of the kiln atmosphere for various air ratios expressed in mole percent.

\begin{tabular}{cccccc}
\hline Air ratio & \multicolumn{5}{c}{ Atmosphere } \\
$\mathrm{m}$ & $\mathrm{N}_{2}$ & $\mathrm{CO}_{2}$ & $\mathrm{O}_{2}$ & $\mathrm{CO}$ & $\mathrm{H}_{2}$ \\
\hline 0.7 & 82.6 & 0.0 & 0.0 & 8.2 & 9.2 \\
0.8 & 89.2 & 0.0 & 0.0 & 5.5 & 5.3 \\
0.9 & 94.9 & 0.0 & 0.0 & 2.8 & 2.3 \\
1.0 & 88.3 & 11.7 & 0.0 & 0.0 & 0.0 \\
1.2 & 86.6 & 9.6 & 3.8 & 0.0 & 0.0 \\
1.4 & 85.4 & 8.2 & 6.4 & 0.0 & 0.0 \\
1.6 & 84.5 & 7.0 & 8.5 & 0.0 & 0.0 \\
\hline
\end{tabular}

alumina. The decomposition of clay takes place at a high temperature and thus hercynite formation is slow at lower temperatures. Thus at $1000^{\circ} \mathrm{C}$, the reduction to iron is considered to be faster than the formation of hercynite. Under the same reducing condition at $1100^{\circ} \mathrm{C}$, decomposition of clay is rapid and thus it possibly leads to the formation of hercynite instead of the formation of metallic iron. At higher temperatures above $1200^{\circ} \mathrm{C}$, diffusion of hercynite to the silica phase or glass phase is considered to occur, and alumina recombines with silica to form mullite and the remaining iron oxide is reduced to iron. This can happen because mullite occurs abundantly at high temperature, and the transformation of $\alpha$-quartz to cristobalite in a reducing atmosphere supports above assumption of the diffusion of hercynite into the silica phase. The diffusion rate also depends on the amount of glass phase present in the clay. Thus hercynite was readily decomposed in the case of the red clay sample fired at $m=0.9$.

The reactions which occurred at $m=0.8$, is quite the same as $m=0.7$, but only hercynite instead of iron was found at $1000^{\circ} \mathrm{C}$. This may be due to the decrease in reducing power to compete with hercynite formation. At $m=0.9$, the reduction to metallic iron was so slow that hercynite formation was dominant below $1200^{\circ} \mathrm{C}$. At $1200^{\circ} \mathrm{C}$, hercynite seems to diffuse and dissociate in the silica phase, forming mullite and cristobalite. Under strongly reducing conditions, such as $m=0.7$ and 0.8 , metallic iron was formed and, while under a mild reducing condition such as $m$ $=0.9$, metallic iron could not be detected by $\mathrm{X}$-ray diffraction analysis and consequently, iron oxide must be combined with silica to form a silicate which dissolved in glass. Sericite was stable up to $1000^{\circ} \mathrm{C}$. At relatively low temperatures, the cristobalite phase was not observed because the transformation to cristobalite occurs at $1470^{\circ} \mathrm{C}^{13), 14}$, but its presence in red clay fired at $1250^{\circ} \mathrm{C}$ may be caused by the ferrous ions which acts as a promotor or a catalyst for the transformation. The peaks of $\alpha$-quartz are shown in Fig. 1. Here, the peaks are higher in the samples fired under oxidizing conditions than in those fired under reducing conditions which shows that ferrous ions act as a strong flux to attack the quartz structure. In a neutral or oxidizing atmosphere, the presence of hematite, confirmed by X-ray analysis, has no effect on the transformation of quartz to other forms ${ }^{15}$. 


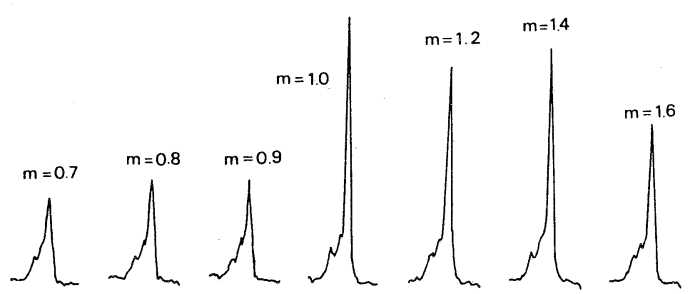

Fig. 1. The comparison of the X-ray diffraction peaks of $\alpha$-quartz of the fired red clay bodies at $1250^{\circ} \mathrm{C}$.

\subsection{ESCA measurement of red clay fired at $1250^{\circ} \mathrm{C}$}

Figure 2 shows the ESCA of clay bodies fired at $1250^{\circ} \mathrm{C}$ under various atmospheric conditions. The vertical lines corresponding to the binding energies of $\mathrm{Fe}^{3+}$ and $\mathrm{Fe}^{2+}$ in an isolated state as well as those of $\mathrm{Fe}_{2} \mathrm{O}_{3}$ and metallic iron in a bulk state are shown at the bottom of the figure. For samples fired at $m=0.8$, that is, in a strongly reducing atmosphere, the two ESCA peaks are attributed to $\mathrm{Fe}^{2+}$ ions and the metallic iron. In the case of the firing in mild reducing atmosphere at $m=0.9$, the peak indicates only the presence of $\mathrm{Fe}^{2+}$. The peaks of $\mathrm{Fe}^{2+}$ ions and fayalite are very simlar and are very difficult to distinguish by means of $\mathrm{ESCA}^{16)}$. In the case of the firing in strongly oxidizing atmospheres, that is, at $m=$ 1. 4, the ESCA spectrum shows a peak of $\mathrm{Fe}_{2} \mathrm{O}_{3}$ in the bulk state which confirms the presence of hematite detected by the X-ray diffraction analysis, but the presence of $\mathrm{Fe}^{3+}$ ions could not be detected as was observed by ESR analysis. This is possibly due to the presence of so small amounts of $\mathrm{Fe}^{3+}$ ions as to be undetectable by ESCA.

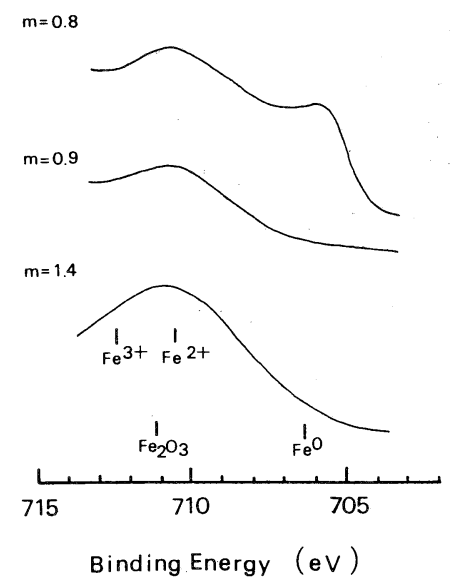

Fig. 2. The ESCA spectra of $\mathrm{Fe} 2 \mathrm{p}_{3 / 2}$ region for fired red clay bodies.

\section{3. $3 \mathrm{ESR}$ analysis of fired clay below $1250^{\circ} \mathrm{C}$}

The authors already revealed from the ESR analysis of the clay fired at $1250^{\circ} \mathrm{C}$ that in the clay fired under oxidizing conditions, the $\mathrm{Fe}^{3+}$ signal as well as the hematite signal were observed, and $\mathrm{Fe}^{3+}$ ions appeared to be trapped in the quartz structure or in the mullite structure ${ }^{17)}$. Hematite was thought to be formed from the degradation of alumina octahedrons in which some iron oxides were present as impurities. The ESR signal of metallic iron shows a slight rise at the low magnetic field and then the pattern falls to a low value at the high magnetic field ${ }^{11}$. Figure 3 shows the ESR spectra of red clay fired at various temperatures in the strongly reducing atmosphere of $m=0.7$. According to the X-ray diffraction data, $\mathrm{Fe}$ metal was found at all temperatures except at $1100^{\circ} \mathrm{C}$ where hercynite occurred abundantly. According to Ishida et al., the red clay fired in a reducing atmosphere produced a signal which corresponded to nonstoichiometric iron oxide but did not mention the presence of hercynite ${ }^{18)}$. Maniatis et al. ${ }^{10)}$ described that hercynite undergoes a magnetic transition at $8 \mathrm{~K}$ but did not mention the magnetic properties near room temperature. The ESR signal observed in the clay fired at $1100^{\circ} \mathrm{C}$ is prominent and is likely to be related to hercynite. The signal of hercynite is not known, and the data of ESR spectrum for hercynite is still lacking. The mutual interaction of various states of iron oxide makes it very difficult to explain the ESR spectra of the fired clay samples even qualitatively ${ }^{18}$. As shown in Fig. 3, the intensity of the signal decreases as the iron phase develops. The patterns generally have

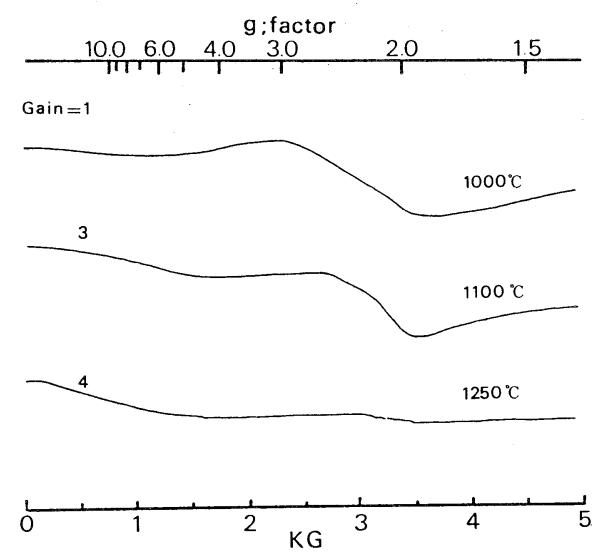

Fig. 3. The ESR spectra of red clay fired at various temperatures in strongly reducing atmosphere of $m=$ 0.7 . 


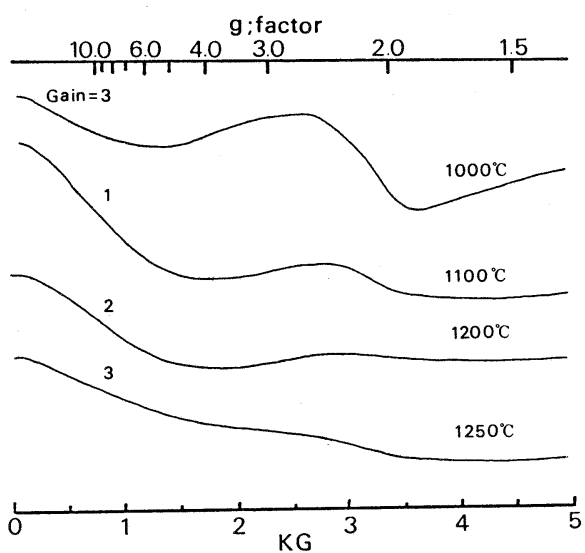

Fig. 4. The ESR spectra of red clay fired at various temperatures in reducing atmosphere of $m=0.8$.

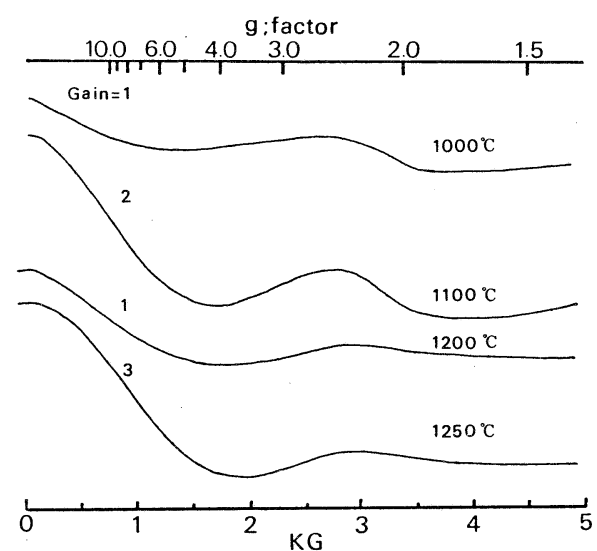

Fig. 5. The ESR spectra of red clay fired at various temperatures in mild reducing atmosphere of $m=0.9$.

two signals, where one signal appears around $1 \mathrm{kG}$ and the other is around $3 \mathrm{kG}$. The signal near $1 \mathrm{kG}$ is similar to the signal of metallic iron, but the signal at the higher magnetic field is unknown. Figures 4 and 5 show the ESR spectra of red clay fired at various temperatures under the atmospheres of the air ratios of 0.8 and 0.9 . The two series of spectra have the same trend as that of $m=0.7$. In Fig. 4, the spectra have two signals like Fig. 3. The signal at the low magnetic field seems to be caused by metallic iron, and the intensity of the signal at the high magnetic field decreases as the iron phase develops. At $1000^{\circ} \mathrm{C}$, where hercynite appears, the peak of the signal is relatively high. In Fig. 5, where the ESR spectra of samples fired under mild reducing conditions are shown, the signal at about $1 \mathrm{kG}$ is rather weak compared with the other figures. It could also be considered that the absence of an iron phase under these mild conditions reduces the interference of the metallic iron signal ; hence, the curves are flattened at the low field. Here, the presence of hercynite detected by $\mathrm{X}$-ray diffraction analysis at temperatures below $1250^{\circ} \mathrm{C}$ also shows the appearance of a signal at a high field. Thus, the hercynite phase seems to be strongly responsible for the signal at the high field.

\section{4 Color characteristic of the fired clay sam-} ples

It was described in the last paper that the atmosphere strongly affects the color of the fired clay samples ${ }^{1}$. That is, in a strongly reducing atmosphere, the color is black; whereas in a mild reducing atmosphere, the color becomes yellowish grey, and in oxidizing conditions, the color is iron red. The samples fired below $1250^{\circ} \mathrm{C}$ in reducing conditions usually obtain a dark grey color and their colors cannot be distinguished by the naked eye. In order to have a better understanding of the color, the color was measured by a color spectrum analyzer and was plotted in a Munsell diagram ${ }^{19)}$. Figure 6 shows the Munsell diagram of red clay fired in various temperatures and atmospheres. This figure as shown was determined at value equals 4 which is nearest to the values of samples varying from 3.44 to 4.64 . In this figure, the circle, the square and the triangle stand for firing temperature of $1000^{\circ} \mathrm{C}$, that of $1100^{\circ} \mathrm{C}$ and that of $1200^{\circ} \mathrm{C}$, respectively. This diagram shows that the color of clay depends on the firing temperature irrespective of the firing atmosphere, because the sample colors are grouped separately with respect to the temper-

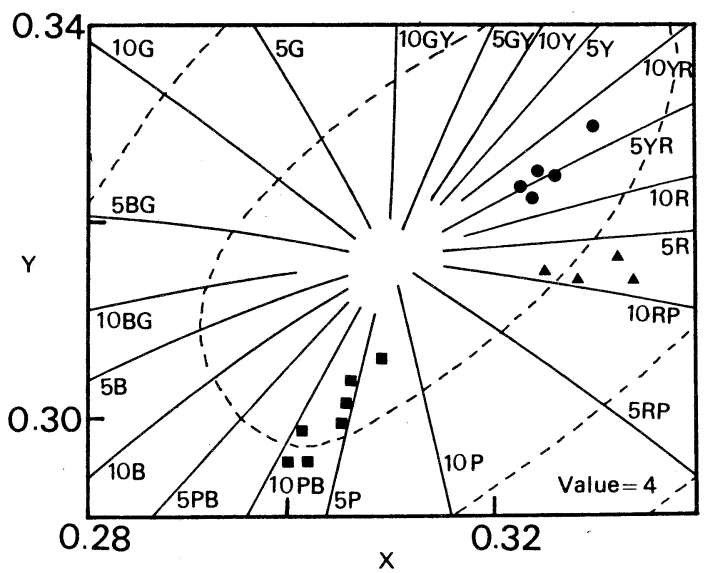

Fig. 6. The Munsell diagram on value $=4$, of the clay bodies fired in various atmospheres below $1250^{\circ} \mathrm{C}$. : indicates the temperature $1000^{\circ} \mathrm{C}, \square$ : indicates the temperature $1100^{\circ} \mathrm{C}$, and $\boldsymbol{\Delta}:$ indicates the temperature $1200^{\circ} \mathrm{C}$ and air ratio from 0.7 to 0.9 . 
ature. At $1000^{\circ} \mathrm{C}$, where the temperature is unsufficient to start high temperature reactions, the color of the samples lie along the neighborhood of $5 \mathrm{YR}$ as shown by circles. At $1100^{\circ} \mathrm{C}$, where hercynite is dominant, the colors of the samples are clustered in the region between $10 \mathrm{~PB}$ and $5 \mathrm{P}$, or in other words, the colors are purplish blue. At $1200^{\circ} \mathrm{C}$, the colors of the fired samples are grouped between $10 \mathrm{RP}$ and $5 \mathrm{R}$, or reddish purple.

Because the brightness is 4 and the chroma is less than 1 for every sample, the colors of all the samples are rather dull. It is also difficult to explain which component determines the color factor as the coloration is not only caused by iron compounds but also by carbon deposition which can blacken the wares fired in the reducing atmosphere ${ }^{20)}$.

\section{Concluding remarks}

The reactions occurring in clay during firing under reducing conditions, have been explained mainly from the viewpoints of the breakdown of the clay structure and the reduction of iron oxide. Under strongly reducing conditions, metallic iron was formed even at low temperatures. The alumina octahedral structure of clay breaks down first and forms hercynite at relatively low temperatures, and at that time, the silica structure is thought to be intact. As the temperature is raised, hercynite seems to diffuse into the silica structure through the glass phase and forms iron silicate and mullite. The ferrous ions such as iron silicate again act as a promoter to transform the low temperature form of the silica structure to the high temperature form, that is, from quartz to cristobalite. The hercynite phase disappears between $1100^{\circ}$ and $1200^{\circ} \mathrm{C}$. The condition for the beginning of the hercynite phase is still unknown, and it seems to form at a temperature where the alumina octahedral structure starts to collapse. The papers describing the presence of hercynite in fired clay under reducing conditions are very few, because the stability of hercynite is sensitive to temperature as well as atmosphere. Unless the atmosphere and temperature are accurately controlled, the results become complex. The atmosphere employed in each experiment was produced by mixing the specific gases, and the flow rate was maintained high enough so that the composition of gases was assumed to be constant. One of the objective of this paper was to investigate the behavior of red clay under various firing conditions.

\section{References}

1) M. Wakamatsu, N. Takeuchi, Ohn Maung, S. Ishida and K. Imai, Yogyo-Kyokai-Shi, 93, 349-56 (1985).

2) J.E. Houseman and C. J. Koenig, J.Am. Ceram. Soc., 54, 82-89 (1971).

3) F. Sandrolini and C. Palmonari, Trans. Brit. Ceram. Soc., 75, 25-32 (1976).

4) F. H. Norton, "Fine Ceramics", McGraw-Hill Book Co. (1970) p. 258-72.

5) A. A. Khalil and A.M. Kabesh, Sprechsaal, 116, 589-92 (1983).

6) K. Ishima, M. Motoyama, G. Hashizume and M. Tanaka, Yogyo-Kyokai-Shi, 88, 312-16 (1980).

7) M. Tanaka and K. Niwano, Yogyo-Kyokai-Shi, 81, 39-44 (1973).

8) M. Tanaka, M. Motoyama, K. Ishima and G. Hashizume, Yogyo-Kyokai-Shi, 84, 220-25 (1976).

9) M. Tanaka, K. Ishima, M. Motoyama and G. Hashizume, Yogyo-Kyokai-Shi, 84, 450-52 (1976).

10) Y. Manitatis, A. Simpoulos, A. Kostikas and V. Perdikatsis, J. Am. Ceram. Soc., 66, 773-81 (1983).

11) M. Wakamatsu, S. Shimizu and M. Kunugi, Research on Effective Use of Energy, 1, 275-80 (1980).

12) H. Etherington and G. Etherington, "Modern Furnace Technology", Charles Griffin Co., Ltd. (1961) p. 477-541.

13) A. Maun, J.Am. Ceram. Soc., 44, 298 (1961).

14) A. Maun, Am.J. Sci., 256, 420 (1985).

15) K. J. D. Mackenzie, Trans. Brit. Ceram. Soc., 68, 97-109 (1969).

16) V. Barron and J. Torrent, Clays and Clay Minerals, 32, 157-58 (1984).

17) T. Caster, G. Neweel, W. C. Holton and C. P. Slichter, J. Chem. Phys., 32, 668-73 (1960).

18) S. Ishida, Y. Fujimura, K. Imai, N. Takeuchi, Ohn Maung and M. Wakamatsu, Yogyo-Kyokai-Shi, 92, 366-73 (1984).

19) M. Khan and F. Schebal, Interceram, [1] , 82-89 (1971).

20) P. Fisher, Ber. Dt. Keram. Ges., 60, 320-27 (1983). 